Gut, 1979, 20, 102-106

\title{
Release of motilin by oral and intravenous nutrients in man
}

\author{
N. D. CHRISTOFIDES, S. R. BLOOM, H. S. BESTERMAN, T. E. ADRIAN, AND \\ M. A. GHATEI
}

From the Department of Medicine, Royal Postgraduate Medical School, Hammersmith Hospital, London

\begin{abstract}
SUMMARY Motilin is a hormonal peptide found in the duodenum and jejunum which potently influences gastrointestinal tract motility. Its role in human physiology is not yet established. After a standard hospital lunch the plasma concentration of motilin showed a small, transient, but significant rise in 28 healthy subjects. Individual food components either stimulated (oral fat) or suppressed release (oral glucose). Plasma motilin levels were, in addition, altered to an equal extent by intravenous nutrients, with glucose and amino acids suppressing release, and intravenous fat causing a significant rise in plasma concentration. These results demonstrate a consistent response to food stimuli, whether oral or intravenous. The release mechanism appears to be complicated and after a balanced meal, containing food components which both stimulate and suppress release, there is only a small net change.
\end{abstract}

The mechanisms involved in the release of plasma motilin in man have not been elucidated. Recently it has been shown that instillation of acid in the duodenum results in a sharp rise of plasma motilin (Mitznegg et al., 1976). Exogenous motilin has been shown to delay gastric emptying of liquids in man (Ruppin et al., 1975) and more recently we have been able to demonstrate a significant enhancement of gastric emptying of solids during a physiological motilin infusion (Christofides et al., 1978). Motilin has also been reported to affect lower oesophageal sphincter pressure (Jennewein et al., 1976). It was therefore of particular interest to investigate the mechanisms regulating the physiological release of endogenous motilin.

\section{Methods}

\section{SUBJECTS}

A previously described radioimmunoassay for motilin was used (Bloom et al., 1976) which was able to detect changes in plasma motilin of $3 \mathrm{pmol} / 1$ with $95 \%$ confidence. Plasma motilin immunoreactivity was measured after an overnight fast in healthy subjects of normal weight in response to two types of stimuli.

Received for publication 16 August 1978
ORAL NUTRITION

1. A standard meal containing two boiled eggs, orange juice, buttered toast and marmalade, composed of $66 \mathrm{~g}$ carbohydrate, $18 \mathrm{~g}$ protein, and $22 \mathrm{~g}$ fat ( 530 calories, $200 \mathrm{ml}$ ) was given after an overnight fast to 28 subjects, 20 men and eight women (103 \pm $3 \%$, mean \pm SEM, of ideal weight) aged 23-62 years (mean 39 years).

2. Six subjects, four men and two women (105 \pm $5 \%$ of ideal weight) aged 22-35 years (mean 27 years) were given $680 \mathrm{~g}$ steamed cod $(515$ calories, $500 \mathrm{ml})$.

3. Seven subjects, five men and two women (104 \pm $5 \%$ of ideal weight) aged $21-35$ years (mean 27 years) were given $120 \mathrm{ml}$ double cream made up to $500 \mathrm{ml}$ with water ( 515 calories).

4. As part of another study 57 people, 40 men and 17 women (103 $\pm 5 \%$ of ideal weight) aged 20-61 years (mean 36 years) ingested $50 \mathrm{~g}$ glucose as a $20 \%$ solution (198 calories, $250 \mathrm{ml}$ ).

\section{INTRAVENOUS NUTRITION}

1. Four subjects, all men $(103 \pm 2 \%$ of ideal weight) aged 22-30 years (mean 25 years) received the following 30 minute isocaloric intravenous infusions in random order on separate days: (i) glucose (20 g as $50 \%$ solution); (ii) amino acids $(25 \mathrm{~g}$ as $250 \mathrm{ml}$ of $10 \%$ aminosol, Kabivitrum Ltd); (iii) fat ( $8 \mathrm{~g}$ as $40 \mathrm{ml}$ of $20 \%$ intralipid, Kabivitrum Ltd). 
2. Arginine $(0.5 \mathrm{~g} / \mathrm{kg} / \mathrm{hour})$ was given as a 30 minute intravenous infusion to 22 subjects, 14 men and eight women (104 $\pm 3 \%$ of ideal weight) aged $25-52$ years (mean 35 years).

\section{CALCULATIONS}

It is well recognised that basal motilin levels are not normally distributed (Bloom et al., 1976). Thus, in order to standardise the changes of motilin from basal, percentage increments were used. The mean $( \pm$ SEM) was used to summarise these percentage increments; the median (and range) was used to summarise the absolute values as is customary for non-normal data. Statistical analysis of the data was carried out using the Wilcoxon sign rank test (on absolute values) comparing post-stimulation values with those at zero time. The linear correlation coefficient between absolute nadir/peak and absolute zero was calculated.

\section{Results}

The fasting motilin levels in all the subjects studied are shown in Fig. 1. The individual values show a skewed distribution, with levels ranging from 4-350 $\mathrm{pmol} / \mathrm{l}$, median $60 \mathrm{pmol} / \mathrm{l}$, and mean of $82 \mathrm{pmol} / \mathrm{l}$.

The effect of the standard meal on plasma motilin is shown in Fig. 2. There was a small and nonsignificant fall in plasma motilin during the 30 minute basal period from $50 \mathrm{pmol} / \mathrm{l}$ (range 14-155) to $42 \mathrm{pmol} / \mathrm{l}$ (range 12-154) at time zero. There was a 22 pmol/1 (range 4-52) incremental rise between 0 and 15 minutes and at 30 minutes a rise of $18 \mathrm{pmol} / 1$ (range
2-61) was seen ( $P<0.01$ and $P<0.05$ respectively), mean percentage increments of $34 \pm 7 \%$ and $21 \pm$ $9 \%$. The 15 minute value was also significantly greater than the -30 minute point $(P<0.05)$. Plasma motilin levels then fell remaining around basal levels until the end of the experiment. There was a significant correlation between the peak motilin concentration and the zero value $(r=0.96$, $\mathrm{n}=28, \mathrm{P}<0.001$ ).

Figure 3 shows the effect of oral fat and glucose on plasma motilin levels. After the ingestion of fat, levels rose from a zero value of $52 \mathrm{pmol} / \mathrm{l}(19-118)$ by $40 \mathrm{pmol} / \mathrm{l}(19-60)$ at 30 minutes and $30 \mathrm{pmol} / \mathrm{l}(3-65)$ at 60 minutes (both $P<0.05$ ), mean percentage increments of $74 \pm 29 \%$ and $57 \pm 22 \%$ respectively. After the ingestion of glucose plasma motilin levels fell from a basal of $70 \mathrm{pmol} / 1$ (4-304) by $29 \mathrm{pmol} / 1$ $(3-274)$ at 60 minutes, $35 \mathrm{pmol} / 1$ (3-320) at 90 minutes and $32 \mathrm{pmol} / 1(2-254)$ at 120 minutes (all $P<0.01$ ), mean percentage decrements of $39 \pm 4 \%$, $51 \pm 4 \%$ and $49 \pm 6 \%$ respectively. There was a significant correlation between the nadir motilin and the value at time zero $(r=0.7, \mathrm{n}=57, \mathrm{P}<0.001)$. After the ingestion of protein there was a small statistically insignificant mean rise.

The effect of intravenous nutrients on plasma motilin levels is shown in Fig. 4. The fasting motilin levels of the four subjects receiving intravenous infusions of fat, glucose, and aminosol were not statistically different on these three occasions. After the 30 minute intravenous infusion of fat, levels rose by $27 \mathrm{pmol} / \mathrm{l}(23-50)$ at 30 minutes and $19 \mathrm{pmol} / 1$ $(6-40)$ at 45 minutes, mean percentage increments of

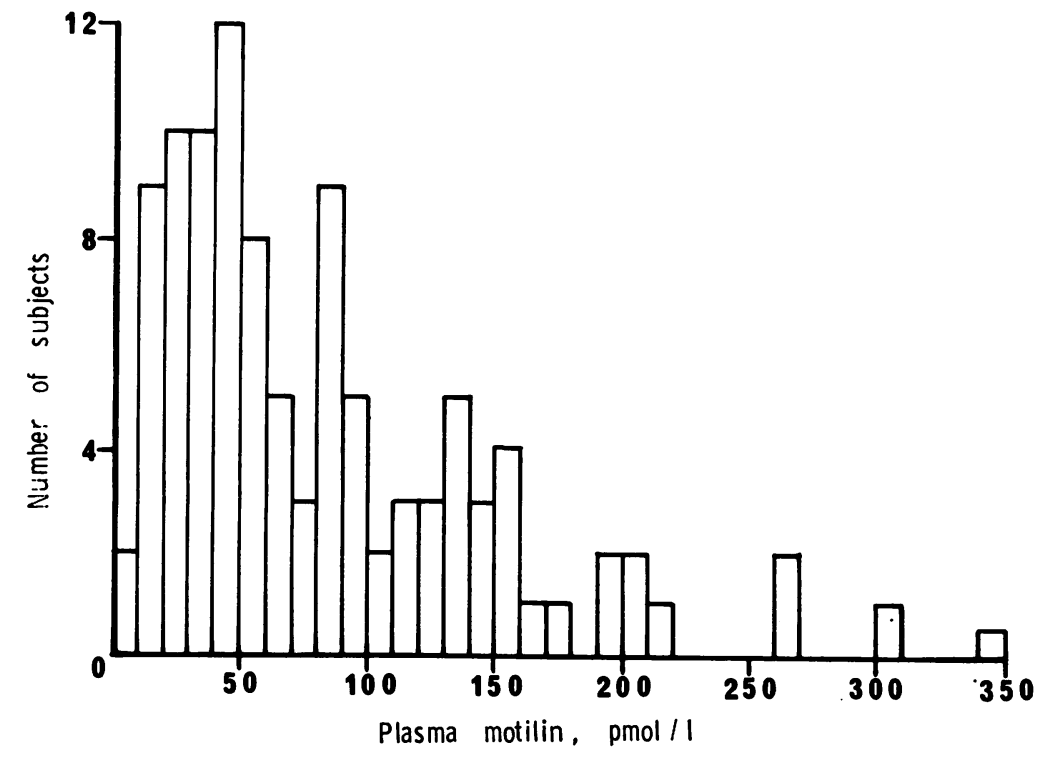

Fig. 1 Fasting plasma motilin concentrations in all 110 subjects used in these studies. 


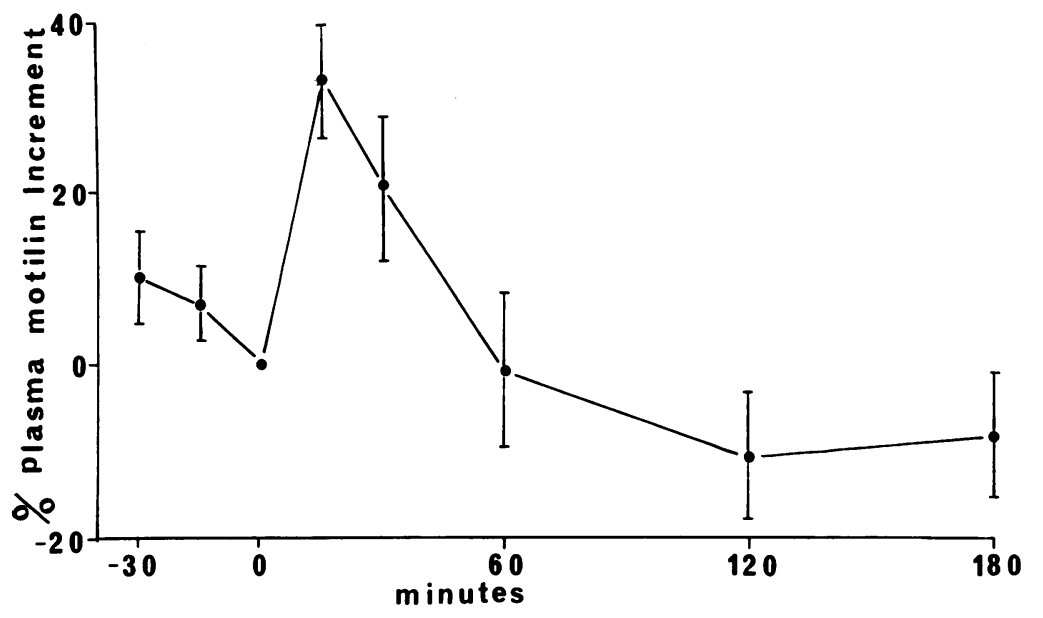

Fig. 2 Percentage increment in plasma motilin in 28 subjects after a standard meal.

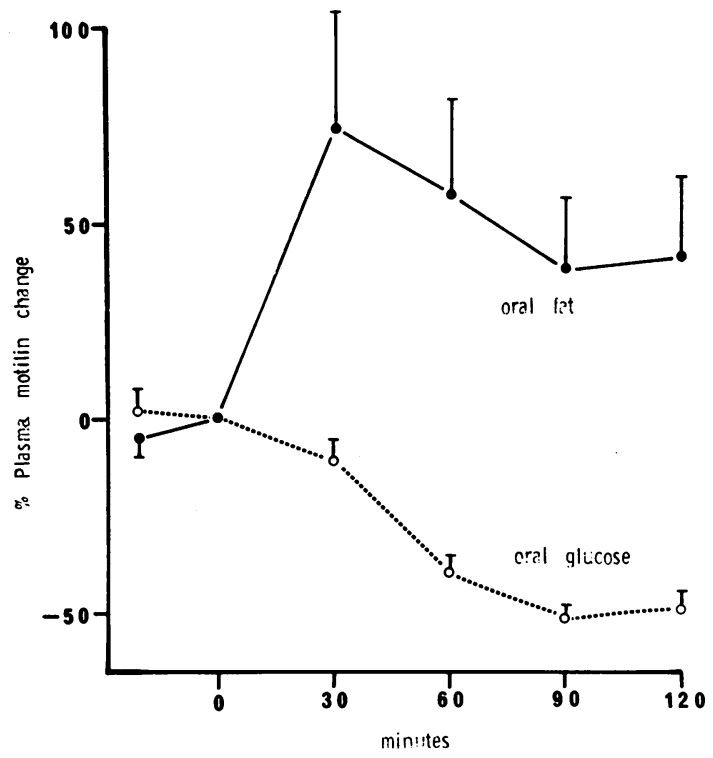

Fig. 3 Percentage increment in plasma motilin after oral ingestion of $120 \mathrm{~g}$ fat $(n=7)$ and $50 \mathrm{~g}$ glucose $(n=57)$.

$56 \pm 10 \%$ and $34 \pm 11 \%$ respectively. Motilin levels then fell to basal values at 60 minutes. After the infusion of glucose plasma motilin levels fell by 27 $\mathrm{pmol} / 1$ (11-44) at 30 minutes and $31 \mathrm{pmol} / 1(10-41)$ at 45 minutes mean percentage decrements of $48 \pm 5 \%$ and $51 \pm 5 \%$ respectively. After infusion of amino acids, motilin levels dropped by $17 \mathrm{pmol} / 1$ (8-32) at 20 minutes $24 \mathrm{pmol} / \mathrm{l}(11-45)$ at 30 minutes and 28 $\mathrm{pmol} / 1$ (14-53) at 45 minutes, mean percentage decrements of $36 \pm 3 \%, 50 \pm 5 \%$ and $60 \pm 6 \%$ respectively. Motilin levels returned to basal values at 60 minutes. A significant fall in plasma levels was also observed after the intravenous infusion of

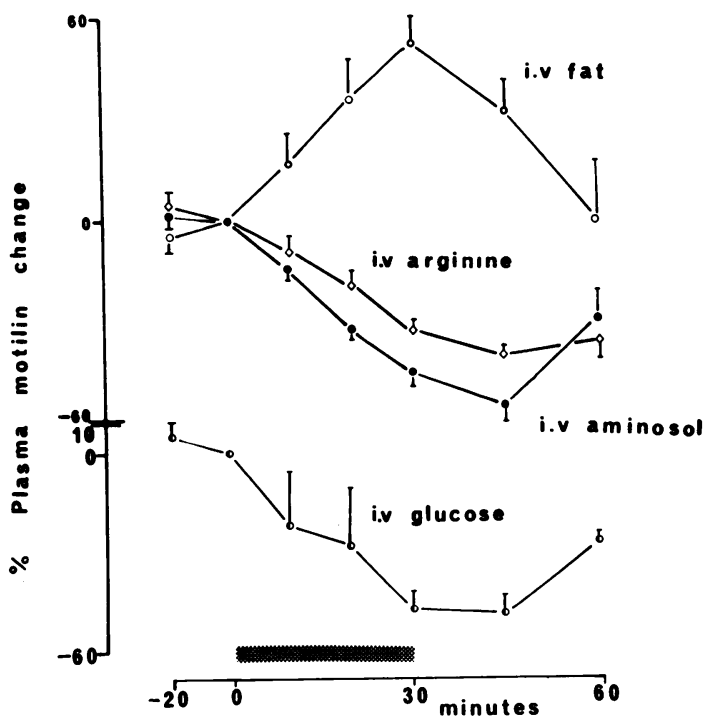

Fig. 4 Percentage change in plasma motilin after intravenous infusions of fat $(8 \mathrm{~g}$ as $40 \mathrm{ml}$ of $20 \%$ intralipid $)(n=4)$, aminoacids $(25 \mathrm{~g}$ as $250 \mathrm{ml}$ of $10 \%$ aminosol $)(n=4)$, and arginine $(0.5 \mathrm{~g} / \mathrm{kg} / \mathrm{hour}, n=22)$ (top) and glucose (20 g as $50 \%$ solution, $n=4)$ (bottom).

arginine. Levels fell from a basal of $60 \mathrm{pmol} / 1$ (20$205)$ by $14 \mathrm{pmol} / 1$ (3-61) at 20 minutes $19 \mathrm{pmol} / \mathrm{l}$ (380 ) at 30 minutes, $25 \mathrm{pmol} / \mathrm{l}(4-89)$ at 40 minutes and $27 \mathrm{pmol} / 1(2-81)$ at 60 minutes (all $\mathrm{P}<0.01$ ) mean percentage decrements of $20 \pm 4 \%, 34 \pm 3 \%, 40 \pm$ $4 \%$ and $38 \pm 6 \%$.

Figure 5 shows the regression line between the nadir plasma motilin in pmol/1 and the zero value after the intravenous administration of arginine. A 


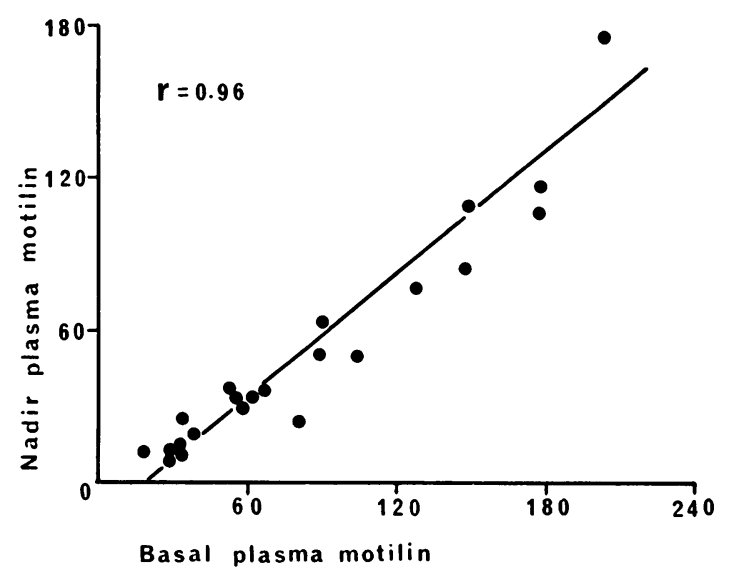

Fig. 5 Correlation between nadir motilin in pmol/l and time zero, after intravenous administration of arginine $(n=22)$.

highly significant correlation was seen $(r=0.96$, $\mathrm{n}=22, \mathrm{P}<0.001)$.

\section{Discussion}

Motilin is a 22 amino acid peptide discovered by Brown and his colleagues in 1971 (Brown et al., 1971) and so called because of its ability to stimulate motor activity in the upper gastrointestinal tract. It is found in high concentrations in the duodenum and jejunum (Bloom et al., 1976). The radioimmunoassay of human plasma motilin presents no special difficulties. Motilin circulates in high concentrations and does not have any sequence similarities with other gastrointestinal hormones. Further, motilin is highly antigenic, making development of antisera easy.

Recently, a sharp rise in plasma motilin levels after instillation of acid in the duodenum has been reported (Mitznegg et al., 1976). However, smaller amounts of gastric acid do not significantly affect plasma levels (unpublished observations). Infusion of exogenous motilin has been reported to inhibit gastric emptying of liquids in man (Ruppin et al., 1975), although, more recently, an accelerating action of motilin on gastric emptying of solids was shown (Christofides et al., 1978). Similarly, exogenous motilin has been shown to profoundly influence lower oesophageal sphincter pressure (Rösch et al., 1976) and decrease intestinal transit time (Ruppin et al., 1976). However, it is not known how relevant these effects might be to the physiological control of gut motility. It is therefore of considerable importance to delineate the factors and magnitude of motilin release. After ingestion of fat, there was a significant rise in plasma motilin levels and an identical rise was also observed after an intravenous infusion of fat. A significant inhibition was observed after both ingestion and intravenous infusion of glucose. These findings suggest the possibility that nutriments may act directly on the motilin cell via the blood stream. After ingestion of protein there was a small, statistically insignificant rise in plasma motilin levels. In contrast a significant inhibition was seen after intravenous infusion of amino acids. The recent finding that motilin is also released after gastric distension (Sarson et al., 1978) might explain this discrepancy, as the protein meal had considerable bulk.

It therefore seems possible that part of the postprandial rise in plasma motilin may be the result of a direct action of nutrients in the circulation. The composition of food appears to determine the extent and direction of the change in plasma motilin and, for example, after a balanced meal only a small rise is seen, because food components tend both to stimulate and suppress its release. The direct effect of food nutrients on release suggests that motilin, like the other upper intestinal hormone GIP, may possibly play a part in metabolic control.

We are grateful for the generous support of the Wellcome Trust. The authors are also indebted to Dr P. Mitznegg, Department of Pharmacology, University of Erlangen-Nuremberg, Germany, for his considerable help and encouragement.

\section{References}

Bloom, S. R., Mitznegg, P., and Bryant, M. G. (1976). Measurement of human plasma motilin. Scandinavian Journal of Gastroenterology, 11, suppl. 39, 47-52.

Brown, J. C., Mutt, V., and Dryburgh, J. R. (1971). The further purification of motilin, a gastric motor activity stimulating polypeptide from the mucosa of the small intestine of hogs. Canadian Journal of Physiology and Pharmacology, 49, 399-405.

Christofides, N. D., Modlin, I. M., Fitzpatrick, M. L., and Bloom, S. R. (1978). Effect of motilin on gastric emptying of solid meals in man. Gut, 19, A436-437 Abstract.

Jennewein, H. M., Bauer, R., Hummelt, H., Lepsin, G., Siewert, R., and Waldeck, F. (1976). Motilin effects on gastrointestinal motility and lower oesophageal sphincter (LES) pressure in dogs. Scandinavian Journal of Gastroenterology, 11, suppl. 39, 63-65.

Mitznegg, P., Bloom, S. R., Domschke, W., Domschke, S., Wünsch, E., and Demling, L. (1976). Release of motilin after duodenal acidification. Lancet, 1, 888-889.

Rösch, W., Lux, G., Domschke, S., Domschke, W., Wünsch, E., Jaeger, E., and Demling, L. (1976). Effect of 13-Nlemotilin on lower esophageal sphincter pressure (LESP) in man (Abstract). Gastroenterology, 70, 931.

Ruppin, H., Domschke, S., Domschke, W., Wünsch, E., Jaeger, E., and Demling, L. (1975). Effects of 13-Nlemotilin in man-inhibition of gastric evacuation and stimulation of pepsin secretion. Scandinavian Journal of Gastroenterology, 10, 199-202.

Ruppin, H., Sturm, G., Westhoff, D., Domschke, S., 
Domschke, W., Wünsch, E., and Demling, L. (1976). Effect of 13-Nle-motilin on small intestinal transit time in healthy subjects. Scandinavian Journal of Gastroenterology, 11, suppl. 39, 85-88.

Sarson, D. L., Christofides, N. D., Albuquerque, R. H.,
Adrian, T. E., Ghatei, M. A., Modlin, I. M., and Bloom, S. R. (1978) Release of gastrointestinal hormones after an oral water load and atropine in man. Gut, 19, A436 Abstract. 